\title{
A COMPARATIVE STUDY BETWEEN I-GEL VERSUS CUFFED ENDOTRACHEAL TUBE IN LAPAROSCOPIC SURGERIES IN ADULT PATIENTS
}

\author{
Samia M. Massoud, Dalal E. M. Soud, Khaled M. Helmy and Mohamed A. Elsayed \\ Department of Anesthesia and Surgical Intensive Care \\ Faculty of Medicine, Zagazig University
}

\begin{abstract}
Background: Invention of the endotracheal tube made administration of anesthesia easy. However, laryngoscopic stimulation of oropharyngolaryngeal structures is associated with hemodynamic stress response. Recently, the I-gel has been invented. It is a new 2nd generation supraglottic airway device with a non-inflatable cuff which has several potential advantages including: easier insertion, minimal risk of tissue compression and stability after insertion. Objective: The aim of this study was to compare the I-gel to the cuffed endotracheal tube in laparoscopic surgeries in adult patients. Patients and Methods: A prospective randomized controlled clinical trial among 80 patients who underwent laparoscopic procedures. They were equally divided into two groups: I-gel and cuffed endotracheal tube (ETT) groups. Both the devices were compared as regards insertion characteristics, hemodynamic stability, gas exchange parameters, peak airway pressure changes and the incidence of postoperative complications. Results: No significant statistical difference between the two groups was found regarding heart rate, $\mathrm{O}_{2}$ saturation, end tidal $\mathrm{CO}_{2}$ and peak airway pressure changes. Regarding mean arterial blood pressure, it was more stable after insertion in the I-gel group $(\mathrm{P}=0.019)$. There was also significant difference in the insertion time $(\mathrm{P}=0.0029)$ and number of insertion attempts $(\mathrm{P}=0.04)$ between the two groups. Regarding ease of insertion of gastric tube, it was easier to be inserted in the ETT group $(\mathrm{P}=0.0001)$. The postoperative complications were higher in the ETT group; for dysphagia $(\mathrm{P}=0.0002)$, dysphonia $(\mathrm{P}=0.0007)$, nausea $(\mathrm{P}=0.0019)$, vomiting $(\mathrm{P}=0.00017)$. However, there was no difference in the presence of blood on the device $(\mathrm{P}=0.396)$. Conclusion: I-gel is a safe airway device during the laparoscopic procedures. It was better than the cuffed ETT regarding hemodynamic stability changes after insertion without affecting gas exchange parameters. Although the complications were higher in the ETT group but the gastric tube insertion was more difficult in the I-gel group.
\end{abstract}

Key words: Airway management, I-gel, Laparoscpic surgeries, Endotracheal tube

\section{INTRODUCTION}

$\mathrm{T}$ Traditional open surgeries are progressing to minimally invasive laparoscopic surgeries. Simultaneously, airway management of patients has also progressed from insufflation to endotracheal tube (ETT) to lesser invasive supraglottic airway devices like I-gel ${ }^{(1)}$. In recent years, the I-gel has been invented. It is a 2 nd generation supraglottic airway device with some distinctive features that sets it apart from other competitors. The I-gel is competing to be the easiest and simplest device. Its main distinguishing feature is the supraglottic component that is made of a thermo-plastic elastomer gel and thus does not require inflation with air $^{(2)}$. There is also an independent gastric drain tube that provides a route to insert a gastric tube into the stomach to aspirate air and residual gastric fluid, while the integral bite block prevents occlusion of the airway during emergence. In common with the LMA, the I-gel is designed for single use and appears to have comparable leak pressures to other supraglottic devices that are currently available ${ }^{(3)}$. The I-gel is a truly unique airway device and represents the culmination of years of extensive research and development. Its design was inspired by the physiology of the perilaryngeal framework itself. The shape, softness and contours accurately mirror the perilaryngeal anatomy to create the perfect fit. This innovative concept means that no cuff inflation is required. Its successful use has been described in randomized controlled studies ${ }^{(4)}$, including studies showing the possibility to intubate through the I-gel ${ }^{(5)}$.

The use of the I-gel is a challenge in laparoscopic surgeries. The cardiopulmonary changes during laparoscopy are complex and depend on the interaction of the patient's pre-existing cardiopulmonary status, the anesthetic technique and several surgical factors including intraabdominal pressure (IAP), carbon dioxide $\left(\mathrm{CO}_{2}\right)$ absorption, patient position and duration of the surgical procedure ${ }^{(6)}$. Although physiological changes are well tolerated by most healthy patients, they could have adverse consequences in the elderly and patients with limited cardiopulmonary reserve ${ }^{(7)}$.

\section{PATIENTS AND METHODS}

In a prospective randomized controlled clinical trial done in Zagazig university hospitals from December 2012 to December 2013, eighty adult patients undergoing laparoscopic procedures under general anesthesia using controlled ventilation, were enrolled in the study. After approval of department of anesthesia, faculty of medicine, Zagazig university, and the research ethics committee and informed consents were obtained from all patients.

Published data from previous similar studies were used to determine the sample size which was approved to be sufficient by the Institutional Review Board (IRB) and department of 
community medicine, faculty of medicine, Zagazig university.

Patients selection was based on certain inclusion and exclusion criteria. Inclusion criteria included the following: (i)Age: 25- 50 years (ii)Both sexes (iii)ASA I-II (iv) elective surgery (v) fasting for at least 8 hours. Patients with reported history of any pathology of the neck or airway, A body mass index $>35 \mathrm{~kg} / \mathrm{m}^{2}$, history of lung diseases or oesophageal reflux were excluded. The patients were equally randomized into two groups: group I (I-gel group) and group II (Endotracheal tube group). Patients were randomly allocated into one of the two groups by research randomizer computer software.

Anesthetic technique was standardized for all patients. All Patients were premedicated 30 minutes preoperatively with midazolam (0.02 $\mathrm{mg} / \mathrm{kg})$, ranitidine $(50 \mathrm{mg})$ and ondansetron $(4 \mathrm{mg})$ I.V. After preoxygenation, anesthesia was induced with propofol $(2 \mathrm{mg} / \mathrm{kg})$ and fentanyl $(1 \mu \mathrm{g} / \mathrm{kg})$ I.V. Neuromuscular blockade for insertion of the airway device was achieved in both groups with cis-atracurium $(0.15 \mathrm{mg} / \mathrm{kg})$.

Device insertion: After an adequate depth of anesthesia had been achieved, each device was inserted. In group I (40 patients), the I-gel was used. The size was chosen according to the patient body weight. It was inserted according to manufacturer's instructions manual. The back, sides and front of the cuff were lubricated with a thin layer of lubricant. The lubricated I-gel was firmly grasped along the integral bite block and positioned so that the I-gel cuff outlet is facing towards the chin of the patient. The patient was in the 'sniffing' position with head extended and neck flexed. The chin was gently pressed down before proceeding to insert I-gel. The leading soft tip was introduced into the mouth of the patient in a direction towards the hard palate. The device was pushed downwards and backwards along the hard palate gently until a definitive resistance was felt. In Group II (40 patients): The cuffed endotracheal tube was inserted using laryngoscope. The size was chosen according to patient age. Gastric tube (GT) was inserted in the I-gel group through the device but in the ETT group was inserted orally or nasally. Gastric tube was inserted 10 minutes after the placement of airway device. In each group, the breathing system was connected then the adequacy of ventilation was assessed by adequate chest movement, chest auscultation, stable oxygenation and capnography.

Maintenance of anesthesia: Anesthesia was maintained with oxygen, isoflurane (1-2\%) and cis-atracurium $(0.03 \mathrm{mg} / \mathrm{kg}$ every $40-50 \mathrm{~min})$. Patients were allocated on controlled mechanical ventilation $(\mathrm{CMV})$ on tidal volume $\left(\mathrm{V}_{\mathrm{T}}\right) 8 \mathrm{ml} / \mathrm{Kg}$ and respiratory rate (RR) $12-14$ breath $/ \mathrm{min}$. Standard monitoring devices were ECG, noninvasive blood pressure, pulse oximetry, end-tidal $\mathrm{CO}_{2}$ and temperature (using oesophageal temperature probe).

Intra-abdominal pressure during laparoscopic procedure was between $12-15 \mathrm{mmHg}$. After the laparoscopic procedure, neuromuscular blockade was reversed with atropine $(0.015 \mathrm{mg} / \mathrm{kg})$ and neostigmine $(0.05 \mathrm{mg} / \mathrm{kg})$. Postoperative complications (e.g. blood on the device, dysphagia, dysphonia, nausea and vomiting) were also noted in the recovery room and 24 hours postoperatively.

Data collection: The main outcome measures were:

-Insertion characteristics of the I-gel or ETT and of the gastric tube like ease of insertion, time taken to insert and attempts taken were noted.

-Hemodynamic and gas exchange parameters: pulse, mean arterial blood pressure (MAP) and oxygen saturation $\left(\mathrm{SpO}_{2}\right)$ were recorded at fixed intervals: Preinduction, after insertion of the I-gel or ETT, after gastric tube insertion, before pneumo-peritoneum, 10 minutes after pneumoperitoneum and postoperatively (between 0 and 24 hours). End-tidal carbon dioxide $\left(\mathrm{EtCO}_{2}\right)$ was recorded at the intervals: after insertion of the I-gel or ETT, after gastric tube insertion, before pneumo-peritoneum and 10 minutes after pneumoperitoneum.

-Peak airway pressure was recorded before pneumo-peritoneum and 10 minutes after pneumoperitoneum.

-Postoperative complications were noted and demonstrated.

Statistical analysis: The collected data were completely reviewed, then the data were computerized and statistically analyzed using SPSS (Statistical package for social sciences) version 18. Numerical variables were examined for normality and sphericity then were presented as mean and standard deviation. On the other hand categorical variables were presented as number of cases and percent. Qualitative variables were compared by Chi-square test. For all tests a $\mathrm{P}$ (probability) value $<0.05$ was considered significant and $\mathrm{P}$ value $<0.01$ was considered highly significant.

RESULTS
Analysis of the demographic characteristics of
patients under study revealed that there was no
statistically significant difference between both
groups regarding the distribution of sex, ASA
classification, mean age and anesthesia time where
P value was > 0.05 in every comparative parameter
(Table 1). As regard the (MAP), it was measured


in the following intervals: preinduction, after device insertion, after gastric tube insertion, before pneumoperitoneum, 10 minutes after pneumoperitoneum and postoperatively. The comparison between preinduction period and after airway device insertion, shows statistical significant difference in group II ( $\mathrm{P}$ value $=0.045)$. But there is no significant difference in group I (P value $=0.952$ ); indicating more hemodynamic stability in the I-gel group (Table 2). There was no significant statistical difference between both groups concerning $\mathrm{O}_{2}$ saturation (Figure 1), end tidal $\mathrm{CO}_{2}$ (Figure 2) and heart rate changes where the $\mathrm{P}$ value was higher than 0.05 in each parameter.

For ease of insertion of the gastric tube (Table 3), The comparison between the two groups shows highly significant difference between the two groups $(\mathrm{P}$ value $=0.0001)$. We failed to insert the gastric tube in $10 \%$ of the I-gel group but we inserted the gastric tube in $90 \%$ of the ETT group from the first attempt.

Regarding peak airway pressure changes, there was no statistical significant difference before or after pneumoperitoneum between the two groups. But there was high statistical significant difference within each group comparing airway pressure before and after pneumoperitoneum $(\mathrm{P}$ value $=<$ 0.0001) (Table 4).

As regard incidence of postoperative complications, it was higher in the ETT group, $\mathrm{P}$ value was highly significant $(\mathrm{P}<0.01)$ for dysphagia, dysphonia, nausea and vomiting. But there was no significant difference concerning the presence of blood on the device after removal $(\mathrm{P}$ value $=0.396)($ Table 5$)$.

Table (1): Demographic data of the patients under study.

\begin{tabular}{|c|c|c|c|c|}
\hline & \multirow{2}{*}{$\begin{array}{c}\text { Group I } \\
\text { I-gel }(n=40)\end{array}$} & \multirow{2}{*}{$\begin{array}{c}\text { Group II } \\
\text { ETT }(n=40)\end{array}$} & \multicolumn{2}{|c|}{ Chi-square } \\
\hline & & & $\mathrm{X}^{2}$ & $\mathrm{P}$ value \\
\hline Male & 10 & 16 & 2.05 & 0.152 \\
\hline Female & 30 & 24 & & \\
\hline ASA I & 32 & 26 & 2.26 & 0.133 \\
\hline ASA II & 8 & 14 & & \\
\hline \multirow{2}{*}{$\begin{array}{c}\text { Age } \\
\text { between } 25-50 y\end{array}$} & mean & mean & & \\
\hline & 26 & 28 & 0.743 & 0.459 \\
\hline Anesthesia time(min) & 70 & 74 & 0.962 & 0.312 \\
\hline
\end{tabular}

$\mathrm{P}>0.05$ was considered non-significant.

Table (2): Changes in mean arterial blood pressure (MAP)

\begin{tabular}{|c|c|c|c|c|c|}
\hline & \multicolumn{2}{|c|}{$\begin{array}{c}\text { Group I } \\
\text { I-gel }(n=40)\end{array}$} & \multicolumn{2}{|c|}{$\begin{array}{c}\text { Group II } \\
\text { ETT }(n=40)\end{array}$} & \multirow[t]{2}{*}{$\mathrm{P}$ value } \\
\hline & Mean & $\pm \mathrm{SD}$ & Mean & $\pm \mathrm{SD}$ & \\
\hline preinduction & 100 & 12 & 102 & 10 & 0.421 \\
\hline After insertion & 100 & 10 & 108 & 16 & $0.019^{*}$ \\
\hline Percentage of change & \multicolumn{2}{|l|}{$0.00 \%$} & \multicolumn{2}{|c|}{$5.80 \%$} & \\
\hline $\mathrm{P}$ value & \multicolumn{2}{|l|}{0.952} & \multicolumn{2}{|c|}{$0.045^{\#}$} & \\
\hline After insertion & 100 & 10 & 108 & 16 & $0.019 *$ \\
\hline After GT & 98 & 11 & 97 & 14 & 0.723 \\
\hline Percentage of change & \multicolumn{2}{|l|}{$2.00 \%$} & \multicolumn{2}{|c|}{$10.10 \%$} & \\
\hline $\mathrm{P}$ value & \multicolumn{2}{|l|}{0.351} & \multicolumn{2}{|c|}{$0.022^{\#}$} & \\
\hline Before pneumoperitoneum & 98 & 14 & 96 & 14 & 0.525 \\
\hline After pneumoperitoneum & 105 & 12 & 107 & 14 & 0.495 \\
\hline Percentage of change & \multicolumn{2}{|l|}{$7.10 \%$} & \multicolumn{2}{|c|}{$13.50 \%$} & \\
\hline $\mathrm{P}$ value & \multicolumn{2}{|l|}{$0.039^{\#}$} & \multicolumn{2}{|c|}{$0.005^{\# \#}$} & \\
\hline After pneumoperitoneum & 105 & 12 & 107 & 14 & 0.495 \\
\hline Postoperative & 102 & 9 & 105 & 8 & 0.119 \\
\hline Percentage of change & \multicolumn{2}{|l|}{$2.80 \%$} & \multicolumn{2}{|c|}{$1.80 \%$} & \\
\hline $\mathrm{P}$ value & \multicolumn{2}{|c|}{0.419} & \multicolumn{2}{|c|}{0.681} & \\
\hline \multicolumn{6}{|c|}{$\begin{array}{l}\text { *P value is significant when }<0.05,{ }^{*} * \mathrm{P} \text { value is highly significant when }<0.01 \text { (comparing the two groups) } \\
{ }^{\#} \mathrm{P} \text { value is significant when }<0.05,{ }^{\# \#} \mathrm{P} \text { value is highly significant when }<0.01 \text { (comparison is done within } \\
\text { the same group) }\end{array}$} \\
\hline
\end{tabular}




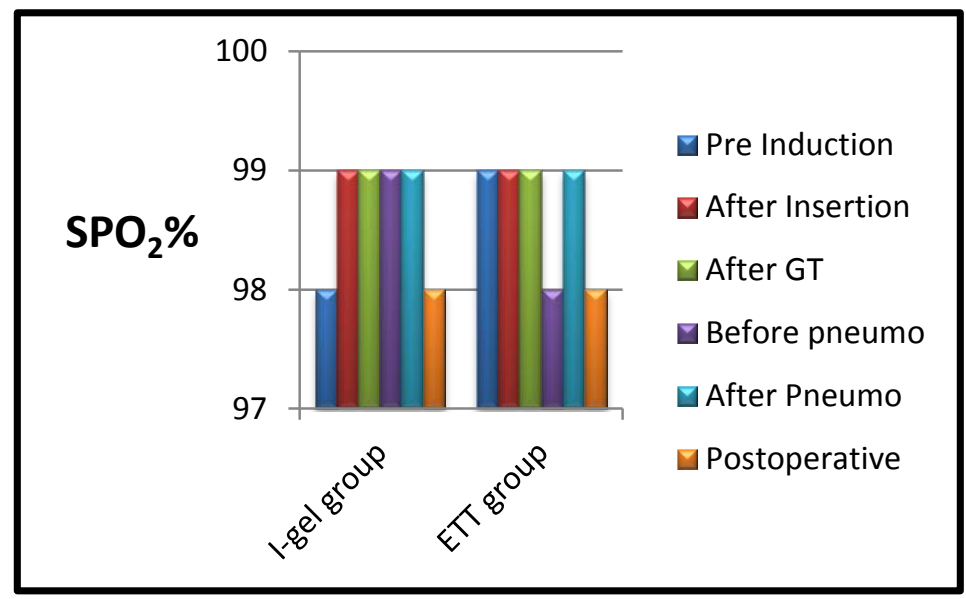

Figure (1): Changes in oxygen saturation $\left(\mathrm{SpO}_{2} \%\right)$.

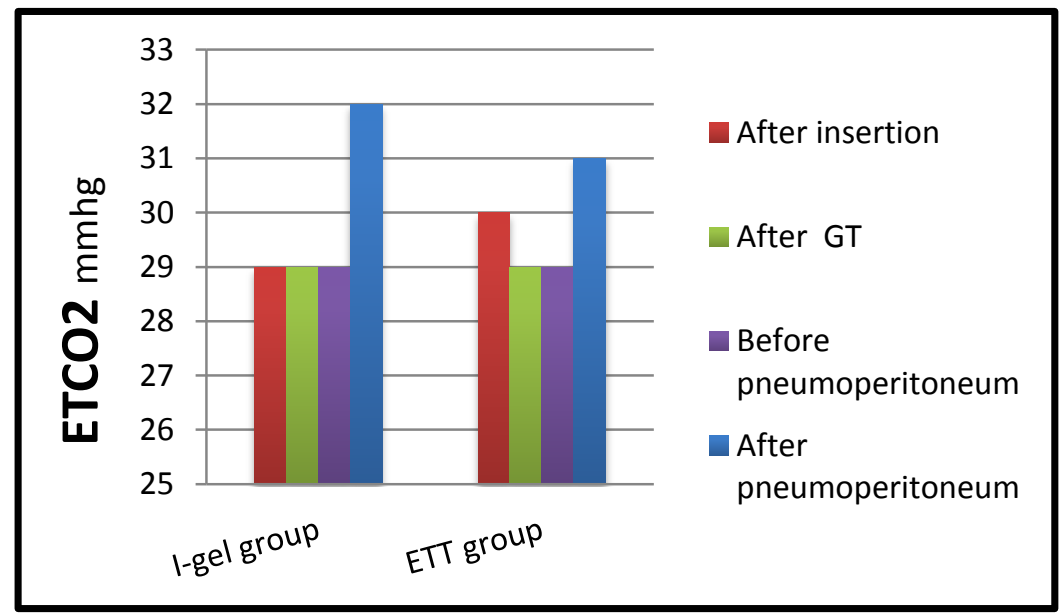

Figure (2): Changes in end tidal $\mathrm{CO}_{2}(\mathrm{mmHg})$.

Table (3): Ease of insertion of the gastric tube.

\begin{tabular}{|c|c|c|c|c|c|c|c|}
\hline & & \multicolumn{2}{|c|}{$\begin{array}{c}\text { Group I } \\
\text { I-gel } \\
(\mathrm{n}=40)\end{array}$} & \multicolumn{2}{|c|}{$\begin{array}{c}\text { Group II } \\
\text { ETT } \\
(\mathrm{n}=40)\end{array}$} & \multicolumn{2}{|c|}{ Chi-square } \\
\hline & & count & $\%$ & count & $\%$ & $\mathrm{X}^{2}$ & $\mathrm{P}$ value \\
\hline \multirow{4}{*}{$\begin{array}{l}\text { No. of gastric tube } \\
\text { Insertion attempts }\end{array}$} & Failure & 4 & $10 \%$ & 2 & $5 \%$ & 20.00 & 0.0001* \\
\hline & 1 & 18 & $45 \%$ & 36 & $90 \%$ & & \\
\hline & 2 & 10 & $25 \%$ & 2 & $5 \%$ & & \\
\hline & 3 & 8 & $20 \%$ & 0 & 0 & & \\
\hline
\end{tabular}

$* \mathrm{P}$ value is highly significant when $<0.01$ 
Table (4): Peak airway pressure changes

\begin{tabular}{cccccccc}
\hline & \multicolumn{2}{c}{$\begin{array}{c}\text { Group I } \\
\text { I-gel }\end{array}$} & \multicolumn{2}{c}{$\begin{array}{c}\text { Group II } \\
\text { ETT }\end{array}$} & \multicolumn{2}{c}{ Chi-square } \\
\cline { 2 - 8 } & Mean & \pm SD & Mean & \pm SD & $X^{2}$ & P value \\
\hline Before pneumoperitoneum & 16 & 3 & 16 & 3.6 & 0.000 & 1.000 \\
\hline After pneumoperitoneum & & & & & & & \\
\hline Percentage of change & \multicolumn{2}{c}{$37.5 \%$} & \multicolumn{2}{c}{$37.5 \%$} & & & \\
\hline
\end{tabular}

\begin{tabular}{ccc}
\hline P value & $\mathbf{< 0 . 0 0 0 1}^{\#}$ & $<\mathbf{0 . 0 0 0 1}^{\#}$ \\
\hline${ }^{\#}$ P value is highly significant when $<0.01$ &
\end{tabular}

Table (5): Postoperative complications of I-gel and ETT groups

\begin{tabular}{|c|c|c|c|c|c|c|c|}
\hline & & \multicolumn{2}{|c|}{$\begin{array}{l}\text { Group I } \\
\text { I-gel } \\
(\mathrm{n}=40)\end{array}$} & \multicolumn{2}{|c|}{$\begin{array}{l}\text { Group II } \\
\text { ETT } \\
(\mathrm{n}=40)\end{array}$} & \multicolumn{2}{|c|}{ Chi-square } \\
\hline & & count & $\%$ & count & $\%$ & $\mathrm{X}^{2}$ & $\mathrm{P}$ value \\
\hline \multirow[t]{2}{*}{ Blood on device } & No & 36 & 90 & 38 & 95 & 0.72 & 0.396 \\
\hline & Yes & 4 & 10 & 2 & 5 & & \\
\hline \multirow{2}{*}{$\begin{array}{c}\text { Dysphagia } \\
\text { between } 0 \text { and } \\
24 \mathrm{hrs}\end{array}$} & No & 38 & 95 & 24 & 60 & 14.05 & $0.0002^{*}$ \\
\hline & Yes & 2 & 5 & 16 & 40 & & \\
\hline \multirow{2}{*}{$\begin{array}{c}\text { Dysphonia } \\
\text { between } 0 \text { and } \\
24 \mathrm{hrs}\end{array}$} & No & 40 & 100 & 30 & 75 & 11.43 & $0.0007^{*}$ \\
\hline & Yes & 0 & 0 & 10 & 25 & & \\
\hline \multirow{2}{*}{$\begin{array}{c}\text { Nausea } \\
\text { between } 0 \text { and } \\
24 \mathrm{hrs} \\
\end{array}$} & No & 36 & 90 & 24 & 60 & 9.6 & $0.0019 *$ \\
\hline & Yes & 4 & 10 & 16 & 40 & & \\
\hline \multirow{2}{*}{$\begin{array}{c}\text { Vomiting } \\
\text { between } 0 \text { and } \\
24 \mathrm{hrs}\end{array}$} & No & 40 & 100 & 28 & 70 & 14.12 & $0.00017^{*}$ \\
\hline & Yes & 0 & 0 & 12 & 30 & & \\
\hline
\end{tabular}

$* \mathrm{P}$ value is highly significant when $<0.01$

\section{DISCUSSION}

The recent advent of newer designs in supralaryngeal airways (SLAs) provides a possible alternative technique to the traditional use of tracheal tubes during laparoscopic surgeries. The advantages of SLAs are related to the fact that they may be inserted easily using a blind technique, and they allow for effective positive pressure ventilation ${ }^{(8)}$.

In this study, after the induction of anesthesia, the I-gel allowed immediate ventilation of the patients with no prolonged lack of ventilation, this may be a feature of the I-gel to be easy to insert. However, there was highly significant difference between I-gel and ETT groups for time of insertion $(P$ value $=0.0029)$. For the number of attempts to insert the airway device, There was significant difference between the two groups; the I-gel insertion was successful after the first attempt in $90 \%$ of patients and the ETT was inserted successfully after the first attempt in $100 \%$ of patients $(\mathrm{P}$ value $=0.04)$. This went in agreement with the large prospective multicentre observ-ational study done by Theiler et al in which they inserted i-gel in 2049 patients and showed that the primary success rate was $93.4 \%{ }^{(9)}$. Also, This was in agreement with Ishwar Singh et al who showed that when the I-gel were studied in 30 anesthetized patients, the success rate of insertion was $96.7 \%^{(10)}$. However, This was different from the results of Wharton et al which showed that when the I-gel was inserted in 40 healthy anesthetized patients, the success rate on the first attempt was $82 \%$ (all devices were placed within 3 attempts) ${ }^{(11)}$.

Gastric tube placement was easier and quicker to insert with the ETT than with I-gel in this study where $90 \%$ was placed successfully at the first attempt while it was inserted successfully in $45 \%$ of the I-gel group at the first attempt. In the I-gel 
group $25 \%$ were inserted during the second attempt, while 5\% were inserted in the ETT. The comparison showed high statistical significant difference $(\mathrm{P}$ value $=0.0001)$. The current study results were comparable to Helmy et al study, where 80 patients were studied, they underwent different surgical procedures under general anesthesia. The success rate for insertion of gastric tube through the I-gel was $95 \%$ compared to overall success rate of $90 \%$ in the current study ${ }^{(12)}$. This did not go in agreement with the study of Richez et al where they found that the insertion of gastric tube in the I-gel was possible in every case ( $100 \%$ success rate) where it was very easy in 41 cases (59\%), easy in 20 (29\%), and difficult in $8(12 \%)^{(13)}$.

In this study, peak airway pressure was measured in the following intervals: before pneumoperitoneum and 10 minutes after pneumoperitoneum, and no statistical significant difference was found throughout the periods of measurement comparing the two groups together. However, the percentage of rise of airway pressure is different from the study of Shyam where he found that the increase in airway pressure in the I-gel and ETT groups was $(38 \%$, $29.9 \%$ respectively before and after pneumoperitoneum, compared to $37.5 \%$ for both groups in the present study ${ }^{(14)}$.

In the current study, mean arterial blood pressure was measured in the following intervals: preinduction, after device insertion, after gastric tube insertion, before pneumo-peritoneum, 10 minutes after pneumo-peritoneum and postoperatively. In the comparison between preinduction period and after airway device insertion, there was no significant difference in Igel group ( $\mathrm{P}$ value $=0.952$ ). However this study was in contrast with the study done by Parul Jindal and his colleagues; they studied hemodynamic responses after insertion of I-gel. They found that there was significant difference in MAP after insertion ${ }^{(15)}$. However, the results of this study approved with Uppal et al who studied 25 patients comparing I-gel and ETT using pressure controlled ventilation, they found several well-established advantages of using I-gel compared with a tracheal tube. The major ones include less hemodynamic upset during induction and maintenance of anesthesia and lower incidence of sore throat ${ }^{(16)}$.

In this study, end tidal $\mathrm{CO}_{2}$ was measured in the following intervals: after device insertion, after gastric tube insertion, before pneumoperitoneum and 10 minutes after pneumoperitoneum. Comparison within the same group showed no significant difference except in the period after pneumoperitoneum where $P$ values $(0.018,0.022)$ in the I-gel and ETT groups respectively with a lower increase in the ETT group (6.4\%). This result did not match the result of study of Shyam in which 60 patients underwent laparoscopic cholecystectomy under general anesthesia. Airway was managed with either I-gel insertion or endotracheal intubation and positive pressure ventilation in 30 patients in each group. He found that the increase in end-tidal $\mathrm{CO}_{2}$ during pneumoperitoneum was higher in the ETT group ${ }^{(14)}$.

In this study, blood was found on I-gel in $4 / 40$ of patients and 2/40 of cases of ETT. This is different from the study made by Uppal et al who found that the incidence of visible blood on the Igel after removal was $12 \%(3 / 25)$ but there was no visible blood on $\mathrm{ETT}^{(11)}$. In another study by David et al, they used I-gel in 100 adult patients, presenting for elective surgery under general anesthesia, and the visible blood on the I-gel after removal was seen only once ${ }^{(17)}$.

In this study, only $5 \%$ of patients complained of dysphagia after I-gel removal and no patients had dysphonia between 0 and 24 hours postoperatively.

There was significant difference between I-gel group and ETT group ( $\mathrm{P}$ value $=0.0002)$, regarding the incidence of dysphagia. The incidence in I-gel group was 5\% but in ETT group was $40 \%$.

Comparing this study with that made by Keijzer et al who studied one hundred nine patients. Patients were examined postoperatively for throat and neck complaints at $1,24 \mathrm{~h}$. They found that the incidence of dysphagia with I-gel was $3.7 \%$ (compared to 5\% in this study). But the incidence of dysphonia with I-gel was different, where we didn't see postoperative dysphonia, they had $8.2 \%$ in their study ${ }^{(18)}$.

In this study the incidence of nausea with I-gel group was (4/40) and no vomiting was noted in $100 \%$ of patients in I-gel group. There was significant difference for nausea between the I-gel group and the ETT group ( $\mathrm{P}$ value $=0.0019)$, in the I-gel group the incidence of nausea was $10 \%$ but in the ETT group the incidence of nausea was $40 \%$. Also there was a highly significant difference between the I-gel group and the ETT group for the incidence of vomiting ( $\mathrm{P}$ value $=0.00017)$. In the I-gel group the percentage was $0 \%$ compared to $30 \%$ in the ETT group.

This was in contrast with the study of Hohlrieder et al who inserted ETT in one hundred female patients undergoing gynecological laparoscopic surgeries. Nausea and vomiting incidence were $(53 \%, 19 \%)$ respectively, compared to $(40 \%$, $30 \%)$ in this study ${ }^{(19)}$. However, in another study 
by Donaldson et al, the incidence of nausea and vomiting with I-gel were comparable to this study where it was $(8 \%, 1 \%)$ respectively, compared to $(10 \%, 0 \%)$ in this study ${ }^{(20)}$.

In conclusion, the I-gel airway is a supraglottic airway device that can deliver effective ventilation even in challenging situations, like in laparoscopic surgeries. It can maintain stable hemodynamics. Its use was associated with lower incidence of nausea and vomiting; the presence of a noninflatable cuff in the pharynx is much less stimulating than an inflatable cuff in the trachea. It has overall incidence of complications less than with the traditional endotracheal tube.

Limitations of the study: It included only low risk patients (ASA I and II) who have normal airway and are not obese. Also, the current study did not compare performance of i-gel with its competitors such as ProSeal LMA and Laryngeal tube.

Recommendations: To use I-gel in challenging situations like laparoscopic surgeries and in risky patients e.g. hemodynamically unstable patients. It proved to be a good alternative to the classic cuffed endotracheal tube.

Acknowledgement: We are grateful to Mr.Asmat Sameja, international sales manager and Mr. David Chapman, airway products manager, Intersurgical Ltd., UK., who provided free samples of the device. The company however was neither involved in protocol preparation nor in data collection and analysis or results.

\section{REFERENCES}

1-Natalini G, Lanza G, Rosano A, Dell' Agnolo P and Bernardini A. Standard Laryngeal Mask Airway and LMAProSeal during laparoscopic surgery. Journal of Clinical Anesthesia 2003; 15(6):428-32.

2-Levitan RM and Kinkle WC. Initial anatomic investigations of the I-gel ${ }^{\mathrm{TM}}$ airway: a novel supraglottic airway without inflatable cuff. Anesthesia 2005;60:1022-1026.

3-Nagappala R, McGoldrick K: Comparison of the LMA-Classic $^{\text {TM }}$ with the New Disposable Soft Seal Laryngeal Mask in Spontaneously Breathing Adult Patients. Survey of Anaesthesiology; 2004, 48: 179.

4-Janakiraman C, Chethan DB, Wilkes AR, Stacey MR, Goodwin N. A randomised crossover trial comparing the i-gel supraglottic airway and classic laryngeal mask airway. Anaesthesia 2009; 64: 6748.

5-Kleine-Brueggeney M, Theiler L, Urwyler N, Vogt A, Greif R. Randomized trial comparing the i-gel and Magill tracheal tube with the single-use ILMA and ILMA tracheal tube for fibreoptic-guided intubation in anaesthetized patients with a predicted difficult airway. Br J Anaesth 2011; 107: 251-7.

6- O'Malley $\mathrm{C}$ and Cunningham AJ. Physiologic changes during laparoscopy. Anesthesiol Clin North America 2001;19:1-19.
7-Joshi G.P. Complications of laparoscopic surgery. Anesthesiol. Clin. North America 2001;19:89-105.

8-Miller Donald M and Camporota Luigi. Advantages of ProSeal ${ }^{\mathrm{TM}}$ and SLIPA ${ }^{\mathrm{TM}}$ airways over tracheal tubes for gynecological laparoscopies. CAN J ANESTH 2006;53(2):188-193.

9-Theiler L, M.Gutzmann, M.Kleine et al. Igel $^{\mathrm{TM}}$ supraglottic airway in clinical practice: a prospective observational multicentre study. British Journal of Anesthesia 2012;109(6):990-5.

10-Ishwar Singh, Monika Gupta and MansiTandon. Comparison of Clinical Performance of $\mathrm{I}-\mathrm{Gel}^{\mathrm{TM}}$ with LMA-Proseal ${ }^{\mathrm{TM}}$ in Elective Surgeries. Indian Journal of Anesthesia 2009;53(3):302-305.

11-Wharton NM, Gibbison B, Gabbott DA, Haslam GM and Cook TM. I- gel insertion by novices in manikins and patients. Journal of the association of Anaesthetists of Great Britain and Ireland 2008;63:991-995

12-Helmy Amr, Hossam M. Atef, Ezzat M Al Taher et al. Comparative study between the I-gel, a new supraglottic airway device, and classical laryngeal mask in anesthetized spontaneously ventilated patients. Saudi J Anaesth 2010;4(3):131-6.

13-Richez B.,Saltel L., Banchereau F., Torrielli R and Cros A. A New Single Use Supraglottic Airway Device with a Non-inflatable Cuff and an Esophageal Vent: An Observational Study of the IGel. Anesth.Analg.2008;106:1137-9.

14-Shyam Maharjan. I-gel for Positive Pressure Ventilation. Journal Of Nepal Medical Association. 2013;52(189):255-259.

15-Parul Jindal, Aslam Rizvi and JP Sharma. Is I-gel a new revolution among supra glottic airway devices? M.E.J. ANESTH 2009;20 (1).

16-Uppal V., Fletcher G. and Kinsella J. Comparison of the I-gel with the cuffed tracheal tube during pressure-controlled ventilation. British Journal of Anesthesia. 2009;102(2):264-8.

17- David A. Gabbott, Beringer R. The i-gel supraglottic airway: A potential role for resuscitation, Resuscitation 2007; 73(1):161-4.

18-Keijzer, Christiaan; Buitelaar, Dirk R., Efthymiou, Katina M. A comparison of postoperative throat and neck complaints after the use of the I-gel ${ }^{\circledR}$ and the La Premiere ${ }^{\circledR}$ disposable Laryngeal Mask. Anesthesia \& Analgesia 2009; 109(4): 1092-1095.

19-Hohlrieder M, Brimacombe J, von GoedeckeA and Keller C. Postoperative nausea, vomiting, airway morbidity and analgesic requirements are lower for the ProSeal laryngeal mask airway than the tracheal tube in females undergoing breast and gynecological surgery. British Journal of Anesthesia 2007;99(4):576-80.

20-Donaldson W, Abraham A, Deighan M, Michalek P. I-gel ${ }^{\mathrm{TM}}$ vs. AuraOnce ${ }^{\mathrm{TM}}$ laryngeal mask for general anaesthesia with controlled ventilation in paralyzed patients.2011;155(2):155-63. 
جيل مع الأنبوبة الحنجرية ذات البالون في الجراحات بالمنظار فى المرضى البالغين. دراسة مقارنة بين أى-

$$
\begin{aligned}
& \text { أ.د/ سامية محم مسعود، أ.د/ دلال السيد محمد سعود، د/ خالد مصطفى حلمى، ط. محمد عبدالبديع السيد. }
\end{aligned}
$$

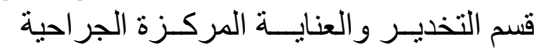

$$
\begin{aligned}
& \text { كلية الطب البشري - جامعة الزقازيق الجرائ }
\end{aligned}
$$

المقدمة:

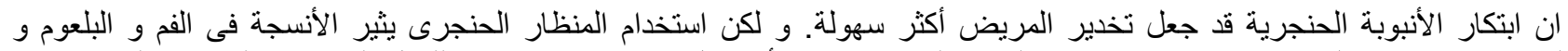

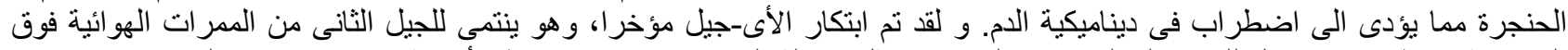

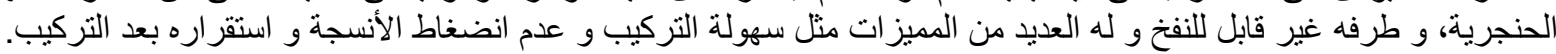

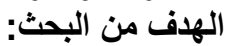
مقارنة الأى-جيل بالأنبوبة الحنجرية ذات البالون فى الجراحات بالمنظار فى المرضى البالغين.

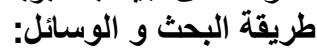

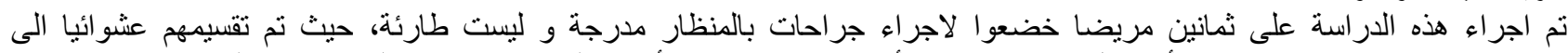

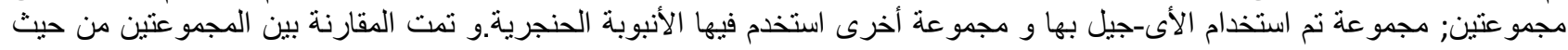

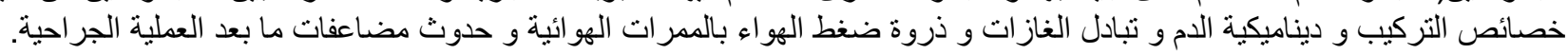
النتائج:

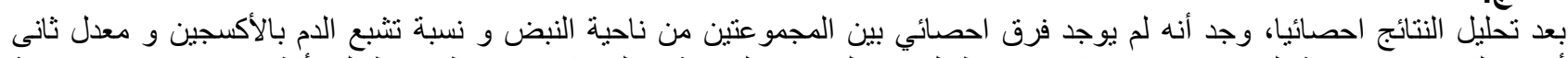

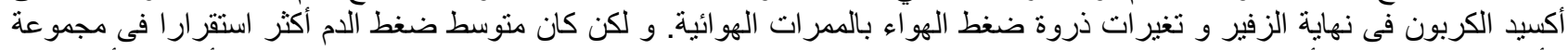

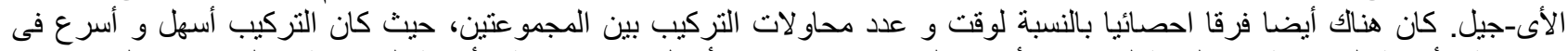

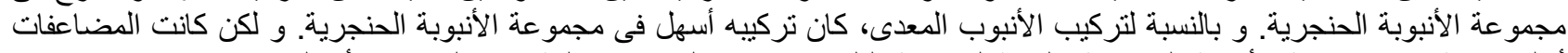

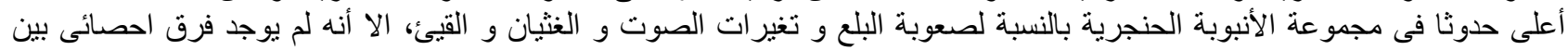

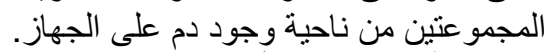

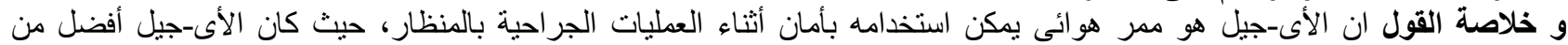

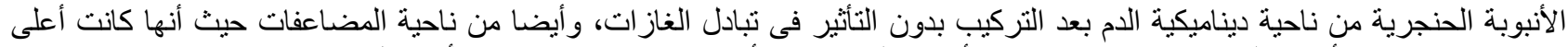

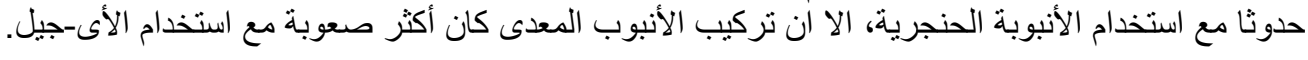

